\title{
Population Levels of Climate Change Fear in the United States
}

\author{
Casey Mace Firebaugh"1*, Tara Rava Zolnikov²,3, Frances Furio ${ }^{3}$, Germaine Ng$^{4}$ \\ ${ }^{1}$ Department of Health Sciences, Central Washington University, Ellensburg, Washington, USA \\ ${ }^{2}$ National University, Department of Community Health, San Diego, California, USA \\ ${ }^{3}$ California Southern University, School of Behavioral Sciences, Costa Mesa, California, USA \\ ${ }^{4}$ University of Washington, Bothell, Washington, USA \\ Email: ^macec@cwu.edu
}

How to cite this paper: Firebaugh, C. M., Zolnikov, T. R., Furio, F., \& Ng, G. (2021). Population Levels of Climate Change Fear in the United States. American Journal of Climate Change, 10, 1-11.

https://doi.org/10.4236/ajcc.2021.101001

Received: January 6, 2021

Accepted: February 7, 2021

Published: February 10, 2021

Copyright (C) 2021 by author(s) and Scientific Research Publishing Inc. This work is licensed under the Creative Commons Attribution International License (CC BY 4.0).

http://creativecommons.org/licenses/by/4.0/

(c) (i) Open Access

\begin{abstract}
There is increasing evidence that climate change, like other natural disasters has the potential for significant human health impacts, including mental health. Fear as a psychological construct concerning climate change is not well understood. An online cross-sectional survey was conducted, targeting a demographically representative sample of Americans $(n=546)$ in terms of ethnicity, age, and gender. Survey questions included demographic information and global questions regarding self-rated anxiety and fear of climate change. Ordinal logistic models were created to determine which demographic factors were most predictive of climate change fear in the US population. Over half of the study sample (50.9\%) indicated being moderately or very afraid of climate change. In the end, only three factors remained significant $(p<0.001)$ in the model; self-reported level of anxiety, political affiliation, and identifying and Hispanic/Latino. Climate change fear is still not understood, especially in terms of its impact on the mental health of the population in general, though prolonged fear can be an antecedent to other mental health disorders. This study had demonstrated that fear of climate change impacts over half of the U.S population. Level of fear differs significantly by demographic. This study has provided evidence that climate change fear impacts a significant proportion of the US population, prompting a need to investigate the potential acute and long-term impacts of this fear on the human psyche. The harms and benefits of the fear response to climate change should be explored as well as potential responses to fear due to climate change.
\end{abstract}

\section{Keywords}

Climate Change, Mental Health, Global Adaption, Fear, Resiliency 


\section{Introduction}

Over the last century, rises in carbon dioxide, methane, and other greenhouse gases have contributed to changes in the climate. Effects related to this increased climate pose great challenges for our world (Trombley et al., 2017). Global climate changes have been evidenced by droughts, extreme storms, melting ice and snow, rising sea levels, rising surface temperature, and increasing variability (Trombley et al., 2017; Frumkin et al., 2008). Climate change impacts not only the environment, but also the humans and animals that live within it (Zolnikov, 2019). Research has shown that the effects of climate change can have a significant impact on human health (Méndez-Lázaro et al., 2018; Frumkin et al., 2008). These impacts are evidenced by various health outcomes associated with weather and climate, including hypothermia from cold, hyperthermia from heat, famine from droughts, increased risk or distribution of diseases from certain climates, and harm and displacement from disasters like fires, floods, tornadoes, and hurricanes (Frumkin et al., 2008).

While there is significant research related to the topic of climate change, and even research related to physical health outcomes associated with the weather and climate, there is less research that focuses specifically on psychological or mental health outcomes associated with climate change (Trombley et al., 2017; Hansen et al., 2012). Recent studies have demonstrated that the belief in climate change and its consequences on human populations is increasing amongst the American public (Sullivan \& White, 2019). The research available provides evidence that mental health may be impacted by climate change in both direct and indirect ways (e.g., firsthand exposure, community well-being) (Clark \& Zolnikov, 2020). Mental health related outcomes associated with climate change may include stress, anxiety, depression, violence, aggression, and loss of community identity (Trombley et al., 2017). Additionally, despair, emotional distress, and fear have been identified as potential mental health related outcomes associated with climate change (Frumkin et al., 2008). In addition to general populations, it has been noted that at-risk populations, such as those experiencing preexisting vulnerabilities, may be at an increased risk of mental health difficulties as a result of the various impacts and outcomes of climate change (Clark \& Zolnikov, 2020).

Fear, an outcome of climate change highlighted in available research, has been described as an evolved response, one that helps people deal with encounters and situations that are threatening (Loewenstein \& Schwartz, 2010). Fear is a feeling, but also an adaptive response that increases hearing acuity, awareness, and memory (Loewenstein \& Schwartz, 2010). Fear related to climate change and our future climate is complex. Public discourse related to the topic of climate change includes concerns about associated dangers, catastrophes, and even extinctions (Hulme, 2008). Some researchers have expected that this fear may motivate the public to support public policies addressing the impacts of climate change (Stern, 2012). Other researchers have noted that while fear motivates 
people to address and eliminate imminent risks, constant risks can indicate to our fear system that fear does not serve a function (Loewenstein \& Schwartz, 2010). Therefore, constancy of risks related to climate change over time could result in a deficiency of fear (Loewenstein \& Schwartz, 2010).

It is clear that the world must adapt to climate changes, as these changes will continue to affect various aspects of life on every continent to varying degrees (Zolnikov et al., 2019). One component of this adaptation will be further exploring and identifying the complex impacts of climate change on mental health (Clark \& Zolnikov, 2020). Understanding the ways in which mental health can be impacted by climate change will provide additional insight into the ways in which populations may be able to be effectively supported (Clark \& Zolnikov, 2020). The expectation of this research was to provide more information related to climate change and fear in human populations. More specifically, the purpose of this study was to investigate demographic factors associated with fear of climate change in the U.S. general population.

\section{Methods}

\subsection{Study Design $\&$ Sampling}

In the summer of 2019, a cross-sectional online survey was distributed to a demographically representative $(n=546)$ sample of American adults (aged 18 and over). Participants were recruited by completed the online survey through Qualtrics which allowed computer and mobile device participation.

\subsection{Measures}

Demographic information including race/ethnicity, Hispanic/Latino identifying, sex/gender, age, income, educational attainment were based upon the US Census data questions (United States Census, 2019). Fear of climate change was measured by a likert-scale based upon a previous study conducted by Whitmarsh and colleagues (Whitmarsh, 2009a, 2009b; Poortinga et al., 2011), asking "How afraid are you of climate change?" The responses ranged from not afraid at all to very afraid. In addition, self-rated anxiety was measured, via a global likert-scale question "Would you consider yourself to be an anxious person?" The possible responses were yes, no, or not sure. Because previous research on climate change perceptions notes political belief as a salient factor (Hornsey et al., 2016), a question about political affiliation was included, which asked participants to classify themselves as either republican, democrat, independent, other, or no affiliation.

\subsection{Data Analysis}

Data were analyzed using IBM SPSS Statistics Version 25. A logistic regression model was performed to determine factors significant to the dependent variable: level of climate change fear. To build the models each independent variable was tested at the bivariate level for a significant association with the dependent variable. Those variables that were significant at the bivariate level $(p<.05)$ were in- 
cluded in the final logistic regression model. The control variables included in the final model were: The model settings tested for main effects of all variables included and significant variables were at the $(p<.05)$ level, due to the ordinal nature of the variables estimated marginal means were not produced. This study was approved by the Central Washington University Human Subjects Research Council (2019-087). Data from this study is not available for public use but is available upon further permission/amendment to the original IRB.

\section{Results}

The sample $(\mathrm{n}=546)$ consisted of a relatively equal proportion of male $48 / .5 \%$ $(\mathrm{n}=265)$ and female respondents, with a minority of respondents identifying as transgender/other/non-binary 50.9\% $(\mathrm{n}=278)$. When asked about race/ethnicity, respondents reported identifying as White $72.5 \%(\mathrm{n}=396)$, Black $14.8 \%(\mathrm{n}=$ 81), American Indian/Alaskan Native $1.8 \%(\mathrm{n}=10)$, Asian 5.5\% $(\mathrm{n}=30)$, Hawaiian/Pacific Islander .5\% $(\mathrm{n}=3)$, Other $4.6 \%(\mathrm{n}=25)$ and the proportion of the sample that identified as Hispanic/Latino was $17.4 \%(\mathrm{n}=95)$. The age distribution of the sample was evenly distributed in the three categories 18 - 34, 35 54, 55 and over [Table 1].

When asked "how afraid are you of climate change" of the entire sample, $21.6 \%$ were very afraid, $29.3 \%$ were moderately afraid, $21.8 \%$ were neutral, $11.7 \%$ were a little afraid, while $15.6 \%$ were not afraid at all [Figure 1].

At the bivariate level the following factors were not significant $(p>.05)$; gender and race/ethnicity. And the following factors were identified as significant at the bivariate level; age $(p<.001)$, identifying as Hispanic/Latino ( $p$ $<.001)$, level of educational attainment $(p<.05)$, level of income $(p=.001)$, political affiliation $(p<.001)$, and self-reported anxiety $(p<.001)$. The significant factors were included in the final model and when tested for main effects, only identifying Hispanic/Latino $(p<.05)$, Political Affiliation $(p<.001)$, and Self-Reported Anxiety $(p<.001)$. Remained significant predictive factors [Table $1]$.

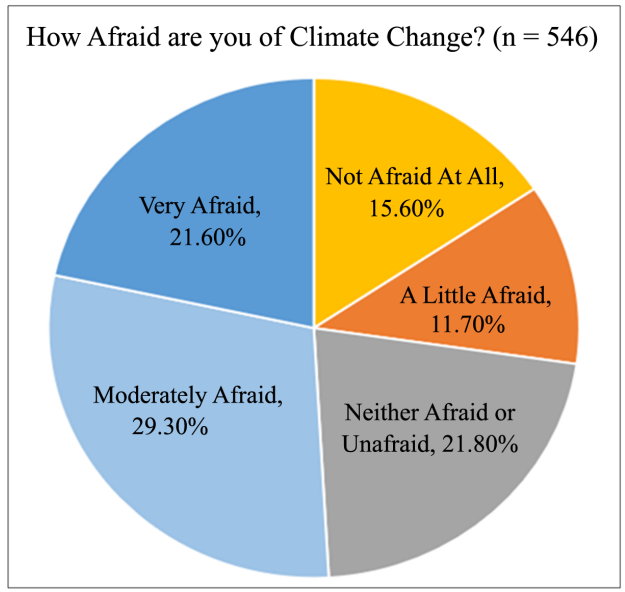

Figure 1. Level of climate fear reported $(n=546)$. 
Table 1. Sample characteristics.

\begin{tabular}{|c|c|c|c|c|c|c|c|}
\hline & Total & $\begin{array}{c}\% \text { of } \\
\text { Total N }\end{array}$ & $\begin{array}{c}\text { Very } \\
\text { Afraid } \\
\mathrm{N}(\%)\end{array}$ & $\begin{array}{c}\text { Moderately } \\
\text { Afraid }\end{array}$ & Neutral & $\begin{array}{c}\text { A } \\
\text { Little } \\
\text { Afraid }\end{array}$ & $\begin{array}{c}\text { Not } \\
\text { Afraid } \\
\text { at All }\end{array}$ \\
\hline & & & 118 & 160 & 119 & 64 & 85 \\
\hline \multicolumn{8}{|l|}{ Gender } \\
\hline Male & 265 & $48.5 \%$ & 65 & 80 & 46 & 24 & 50 \\
\hline Female & 278 & $50.9 \%$ & 53 & 79 & 73 & 39 & 34 \\
\hline Non-Binary/Other & 3 & $0.6 \%$ & & 1 & & 1 & 1 \\
\hline \multicolumn{8}{|l|}{ Age } \\
\hline $18-34$ & 166 & $30.4 \%$ & 40 & 50 & 46 & 17 & 13 \\
\hline $35-54$ & 188 & $34.4 \%$ & 53 & 56 & 40 & 15 & 24 \\
\hline 55 and over & 192 & $35.2 \%$ & 25 & 54 & 33 & 32 & 48 \\
\hline \multicolumn{8}{|l|}{ Hispanic/Latino ${ }^{* *}$} \\
\hline Yes & 95 & $17.4 \%$ & 31 & 33 & 13 & 9 & 9 \\
\hline No & 451 & $82.6 \%$ & 87 & 127 & 106 & 55 & 76 \\
\hline \multicolumn{8}{|l|}{ Race } \\
\hline White & 396 & $72.5 \%$ & 83 & 122 & 73 & 51 & 67 \\
\hline Black & 81 & $14.8 \%$ & 17 & 19 & 30 & 8 & 7 \\
\hline $\begin{array}{c}\text { American Indian or } \\
\text { Alaskan Native }\end{array}$ & 10 & $1.8 \%$ & 3 & 1 & 2 & 2 & 2 \\
\hline Asian & 30 & $5.5 \%$ & 5 & 9 & 10 & 2 & 4 \\
\hline $\begin{array}{l}\text { Native Hawaiian or } \\
\text { Pacific Islander }\end{array}$ & 3 & $0.5 \%$ & 1 & 0 & 1 & 0 & 1 \\
\hline Other & 25 & $4.6 \%$ & 8 & 9 & 3 & 1 & 4 \\
\hline \multicolumn{8}{|l|}{ Educational Attainment } \\
\hline No Secondary Education & 6 & $1.1 \%$ & 0 & 2 & 4 & 0 & 0 \\
\hline High school & 129 & $23.6 \%$ & 26 & 31 & 35 & 16 & 21 \\
\hline Technical Associates & 56 & $10.3 \%$ & 6 & 23 & 11 & 7 & 9 \\
\hline Some College No Degree & 129 & $23.6 \%$ & 19 & 41 & 32 & 16 & 21 \\
\hline Bachelors & 128 & $23.4 \%$ & 26 & 41 & 25 & 16 & 20 \\
\hline Masters & 77 & $14.1 \%$ & 32 & 18 & 10 & 6 & 11 \\
\hline Doctoral & 21 & $3.8 \%$ & 9 & 4 & 2 & 3 & 3 \\
\hline \multicolumn{8}{|l|}{ Income Level } \\
\hline Less than $\$ 25,750.00$ & 136 & $24.9 \%$ & 29 & 37 & 33 & 14 & 23 \\
\hline$\$ 25,751-50,000$ & 126 & $23.1 \%$ & 19 & 36 & 34 & 17 & 20 \\
\hline$\$ 50,001-75,000$ & 106 & $19.4 \%$ & 19 & 35 & 23 & 14 & 15 \\
\hline$\$ 75,001-125,000$ & 105 & $19.2 \%$ & 20 & 32 & 22 & 11 & 20 \\
\hline$\$ 125,001$ and over & 73 & $13.4 \%$ & 31 & 20 & 7 & 8 & 7 \\
\hline
\end{tabular}


Continued

\begin{tabular}{|c|c|c|c|c|c|c|c|}
\hline \multicolumn{8}{|c|}{ Political Affiliation ${ }^{* *}$} \\
\hline Republican & 167 & $30.6 \%$ & 37 & 37 & 29 & 26 & 38 \\
\hline Democrat & 205 & $37.5 \%$ & 58 & 73 & 37 & 21 & 16 \\
\hline Independent & 137 & $25.1 \%$ & 19 & 41 & 39 & 17 & 21 \\
\hline Other & 5 & $0.9 \%$ & 1 & 0 & 2 & 0 & 2 \\
\hline No Preference & 32 & $5.9 \%$ & 3 & 9 & 12 & 0 & 8 \\
\hline \multicolumn{8}{|l|}{ Anxious Person ${ }^{* *}$} \\
\hline Yes & 223 & $40.8 \%$ & 70 & 76 & 44 & 19 & 14 \\
\hline No & 275 & $50.4 \%$ & 42 & 68 & 57 & 40 & 68 \\
\hline Not Sure & 48 & $8.8 \%$ & 6 & 16 & 18 & 5 & 3 \\
\hline
\end{tabular}

\section{Discussion}

Climate change can have significant effects on population health, although mental health has been historically less researched. The effects on mental health from climate change may be expansive and could include anxiety for the future, stress for exposure to natural disasters, or fear for the future of the planet (e.g. catastrophe, extinction, etc.). This type of fear is important to understand to address it in affected populations and improve mental health. Moreover, it has been speculated that by fear, policies and programs may be improved to encourage behavior change in the public (Stern, 2012). Other researchers have noted that while fear motivates people to address and eliminate imminent risks, continual mention of risks can cause a desensitization of information and work against fear-based motivation (Loewenstein \& Schwartz, 2010).

This study sought to understand fear and climate change and classify this population by using demographic and other identifying information. The results from this study found that most Americans have some degree of fear towards climate change and just over half are moderately to very afraid. In terms of gender, race/ethnicity, identifying Hispanic/Latino, age, the study sample was consistent with the U.S. Census Bureau (2020).

Interestingly, one of the first papers to explore climate change, beliefs, and demographic associations (most notably gender) in the United States outlined the archetype of the conservative white male in the United States as a climate change denier (McCright \& Dunlap, 2011). These demographic associations have been replicated in other studies outside of the United States as well (Krange, Kaltenborn, \& Hultman, 2019). However, the data in this study found that gender may not play as significant role in climate change belief/fear as previously studied, perhaps indicating the conservative women are less fearful of climate change than previously thought, or perhaps there is a generational gap with older conservative men differing in climate change beliefs from their younger peers. A Pew Research poll conducted in 2015 found that women were more likely than men to report concern regarding climate change; more specifi- 
cally, $69 \%$ of women were concerned about the effects of climate change and accompanying personal harm, while fewer than half of men (48\%) reported the same (Zainulbhai, 2015). However, a meta-analysis by Hornsey and colleagues (2016) found that variables, such as education, sex, subjective knowledge, and experience of extreme weather events, were less significant in determining in predictive power by constructs of values, ideologies, worldviews and political orientation. While the sample was mostly representative of the US sample in terms of gender, transgender/non-binary/other identifying individuals may have been under-represented in this study sample, consistent with other population health studies (Meerwijk \& Sevelius, 2017).

\subsection{Political Affiliation}

Consistent with previous studies, climate change perceptions are significantly associated with political affiliation (Ballew et al., 2019; Hornsey et al., 2016). However, previous research primarily focuses on the dichotomy of the republican (conservative) versus the democratic (liberal) parties in the United States, two-party political system. While conservatives or republicans in the United States are generally portrayed and perceived to be climate change skeptics, the results of this study found that in fact, the majority of conservative-identifying individuals were (moderately or very) afraid of climate change, indicating not only a belief in its existence but a genuine concern. Our sample consisted of an approximate equal number of republican and democratic identifying individuals, but also included a large independent party, and other or non-affiliated groups also emerged. However, all political groups demonstrated this pattern, with the majority of members reporting that they were moderately to very afraid. The beliefs and perceptions surrounding climate change may evolve quickly within demographic groups.

\subsection{Self-Rated Anxiety}

Self-reported anxiety was statistically significantly with climate change fear. These results are not surprising, as climate change is a longstanding issue and chronic mental health disorders can cause anxiety, depression, and even posttraumatic stress disorders (U.S. Global Change Research Program, 2016). More specifically, flooding and droughts are associated with anxiety, depression, and posttraumatic stress, while losses from these natural disasters can contribute to depression and anxiety (U.S. Global Change Research Program, 2016). Up to $50 \%$ of individuals exposed to a weather disaster are at risk for negative mental health effects, like depression and anxiety. To date, it has been estimated that $14 \%$ of the worldwide burden of disease is attributed to neuropsychiatric disorders (e.g., due to the long-term negative outcomes of depression and anxiety, alcohol, substance use disorders, etc.), all conditions which are known risk factors for individuals exposed to severe climate change (Prince et al., 2007). Anxiety also arises with physical challenges that occur from stifling heat waves, that 
can cause discomfort as individuals struggle to adapt; studies show that climate change beyond a person's control can give rise to stress, anxiety, and depression. Obradovich and colleagues (2018) also noted that increased temperature and precipitation are each correlated with an increase of mental health issues.

\subsection{Implications}

Given the high proportion of fear of climate change in the American population, it is important for public and mental health professionals to understand the more about the impacts of climate change fear in the daily lives and functioning of the general population. The effects are twofold in that this information can help mitigate adverse mental health in affected populations and also, understand ways to motive individuals to encourage positive change addressing climate change. In addition, this study determined that when controlling for age, gender, educational attainment, and income self-identified anxiety and climate change fear were significantly associated. Although this study could not provide conclusive evidence whether anxiety precedes climate change fear or whether climate change fear precedes anxiety, there appears to be a relationship between these variables that should be explored further. Moreover, understanding how these groups are associated with state of high climate change is important to address the issue of mental health problems caused by anxiety due to climate change. As such, living in a perpetual state of fear can be damaging to daily function and mental and physical health (Moller, 2017), further studies should investigate the positive and negative potentials for fear in relation to climate change. Positive fear can be a motivation to act, including becoming aware or educating, preparing for natural disasters or emergencies (National Research Council [NRC], 1991). However, negative fear, such as consuming thoughts, emotional disturbance of anxiety that inhibits daily functioning should be examined to determine appropriate mental interventions. Finally, it should be mentioned that there are limitations on determining the variables that are associated with the fear of climate change as clinical research on this field is still limited.

\subsection{Limitations}

Climate change can be somewhat of an abstract term, as people could range in definitions of it, from heat waves to increased greenhouse gases. Climate change research, in particular the social and behavioral aspects of climate change is impaired by a lack of streamlined terminology, measurement, and approach to create generalizable data and findings. In the early days of the climate change crisis, determining the terminology between the terms global warming and climate change created some discrepancy in research aims/findings. Likewise, the fear, concern, belief realm of climate change research is limited by this lack of internationally standardized approach. In addition, fear was measured by one global likert-scale question. More in-depth understanding of the construct of fear in the context of climate change should be explored. While this study was 
not able to shed light on some of the complex psychological nuances of perceived fear and results of fear, this study was able to provide an important finding: the number of people in a large sample who report fear of climate change. Whatever that means, requires further examination. Finally, this study was conducted via an online platform, which lends itself to a more tech savvy sample population.

\subsection{Future Research}

Future research should delve into understanding if fear related to climate change is a mental health crisis, a political crisis, or existential crisis. Further studies should investigate the positive and negative potentials of fear in relation to climate change. Positive fear can be motivation to act, including becoming aware or educating, preparing for natural disasters or emergencies. However, negative fear, such as consuming thoughts, emotional disturbance of anxiety that inhibits daily functioning should be examined to determine appropriate mental interventions. Delineating between these two upstream contributors can help in easing fear in populations caused by climate change outcomes.

\section{Conclusion}

This study had demonstrated that fear of climate change impacts over half of the U.S population. Level of fear differs significantly by demographic. It is important to identify climate change-related mental health risks as a mainstream health priority.

\section{Acknowledgements}

The manuscript team would like to thank Anne Egger at Central Washington University, the PI on the NSF grant as well as Germaine Ng of University of Washington, Bothell for her participation in survey building during the REU program.

\section{Funding Statement}

This research was funded by NSF Grant Number 1559862 titled: REU Site: Hazards and Risks of Climate Change in the Pacific Northwest.

\section{Conflicts of Interest}

The authors declare no conflicts of interest regarding the publication of this paper.

\section{References}

Ballew, M. T., Leiserowitz, A., Roser-Renouf, C., Rosenthal, S. A., Kotcher, J. E., Marlon, J. R. et al. (2019). Climate Change in the American Mind: Data, tools, and Trends. Environment: Science and Policy for Sustainable Development, 61, 4-18. https://doi.org/10.1080/00139157.2019.1589300 
Clark, T., \& Zolnikov, T. (2020). Climate Change and Mental Health. In R. Brears (Ed.), The Palgrave Handbook of Climate Resilient Societies (pp. 1-26). Cham: Palgrave Macmillan. https://doi.org/10.1007/978-3-030-32811-5 2-1

Frumkin, H., Hess, J., Luber, G., Malilay, J., \& McGeehin, M. (2008). Climate Change: The Public Health Response. American Journal of Public Health, 98, 435-445.

Hansen, J., Sato, M., \& Ruedy, R. (2012). Perception of Climate Change. Proceedings of the National Academy of Sciences, 109, E2415-E2423. https://doi.org/10.1073/pnas.1205276109

Hornsey, M. J., Harris, E. A., Bain, P. G., \& Fielding, K. S. (2016). Meta-Analyses of the Determinants and Outcomes of Belief in Climate Change. Nature Climate Change, 6, 622-626. https://doi.org/10.1038/nclimate2943

Hulme, M. (2008). The Conquering of Climate: Discourses of Fear and Their Dissolution. The Geographical Journal, 174, 5-16. https://doi.org/10.1111/j.1475-4959.2008.00266.x

Krange, O., Kaltenborn, B. P., \& Hultman, M. (2019). Cool Dudes in Norway: Climate Change Denial among Conservative Norwegian Men. Environmental Sociology, 5, 1-11. https://doi.org/10.1080/23251042.2018.1488516

Loewenstein, G., \& Schwartz, D. (2010). Nothing to Fear but a Lack of Fear: Climate Change and the Fear Deficit. Summit 2010, G8/G20.

McCright, A. M., \& Dunlap, R. E. (2011). Cool Dudes: The Denial of Climate Change among Conservative White Males in the United States. Global Environmental Change, 21, 1163-1172. https://doi.org/10.1016/j.gloenvcha.2011.06.003

Meerwijk, E. L., \& Sevelius, J. M. (2017). Transgender Population Size in the United States: A Meta-Regression of Population-Based Probability Samples. American Journal of Public Health, 107, 216. https://doi.org/10.2105/AJPH.2016.303578a

Méndez-Lázaro, P. A., Pérez-Cardona, C. M., Rodríguez, E., Martínez, O., Taboas, M., Bocanegra, A., \& Méndez-Tejeda, R. (2018). Climate Change, Heat, and Mortality in the Tropical Urban Area of San Juan, Puerto Rico. International Journal of Biometeorology, 62, 699-707. https://doi.org/10.1007/s00484-016-1291-Z

Moller, M.D. (2017). 2017 Neuroscience Education Institute (NEI) Congress, Presentation on the Effects of Chronic Fear on a Person's Health.

https://www.ajmc.com/view/the-effects-of-chronic-fear-on-a-persons-health

National Research Council (1991). U.S. National Committee for the Decade for Natural Disaster Reduction Commission on Geosciences, Environment, and Resources. National Washington DC: Academy Press.

Obradovich, N., Migliorini, R., Paulus, M. P., \& Rahwan, I. (2018). Empirical Evidence of Mental Health Risks Posed by Climate Change. Proceedings of the National Academy of Sciences of the United States of America, 115, 10953-10958. https://doi.org/10.1073/pnas.1801528115

Poortinga, W., Spence, A., Whitmarsh, L., Capstick, S., \& Pidgeon, N. F. (2011). Uncertain Climate: An Investigation into Public Scepticism about Anthropogenic Climate Change. Global Environmental Change, 21, 1015-1024. https://doi.org/10.1016/j.gloenvcha.2011.03.001

Prince, M., Patel, V., Saxena, S., Maj, M., Maselko, J., Phillips, M. R., \& Rahman, A. (2007). No Health without Mental Health. The Lancet, 370, 859-877.

https://doi.org/10.1016/S0140-6736(07)61238-0

Stern, P. C. (2012). Fear and Hope in Climate Messages. Nature Climate Change, 2, 572-573. https://doi.org/10.1038/nclimate1610

Sullivan, A., \& White, D. D. (2019). An Assessment of Public Perceptions of Climate 
Change Risk in Three Western US Cities. Weather, Climate, and Society, 11, 449-463. https://doi.org/10.1175/WCAS-D-18-0068.1

Trombley, J., Chalupka, S., \& Anderko, L. (2017). Climate Change and Mental Health. American Journal of Nursing, 117, 44-52. https://doi.org/10.1097/01.NAJ.0000515232.51795.fa

U.S. Census Bureau (2020). National Population by Characteristics 2019-2020. https://www.census.gov/data/tables/time-series/demo/popest/2010s-national-detail.ht $\underline{\mathrm{ml}}$

U.S. Global Change Research Program (2016). The Impacts of Climate Change on Human Health in the United States: A Scientific Assessment. US Global Change Research Program.

Whitmarsh, L. (2009a). What's in a Name? Commonalities and Differences in Public Understanding of "Climate Change" and "Global Warming". Public Understanding of Science, 18, 401-420. https://doi.org/10.1177/0963662506073088

Whitmarsh, L. (2009b). Behavioural Responses to Climate Change: Asymmetry of Intentions and Impacts. Journal of Environmental Psychology, 29, 13-23.

https://doi.org/10.1016/j.jenvp.2008.05.003

Zainulbhai, H. (2015). Women, More than Men, Say Climate Change Will Harm Them Personally. Pew Research Center.

Zolnikov, T. R. (2019). Global Adaptation and Resilience to Climate Change. Cham: Palgrave Pivot. https://doi.org/10.1007/978-3-030-01213-7

Zolnikov, T. R., Ramirez-Ortiz, D., Raymond, J., Chambers, D., Brears, R., Cook, D., \& Zolnikov, T. (2019). A Scoping Review on Global Climate Change Vulnerability, Adaptation, and Resiliency. Spotlight on Climate Change Research.

https://doi.org/10.35831/sorccr/26072019trz 